\title{
„War es das wert ?“
}

\section{Gedanken eines Neunzehnjährigen}

War es das wert? Ich glaube, das ist die meist gefragteste Frage hier, obwohl sie gleichzeitig auch wiederum die am wenigsten gefragte Frage ist!

Jeder hier hat sie sich schon selbst gestellt und selbst schon beantwortet. In den Köpfen derjenigen, die sie sich gestellt haben, wird sie immer mit nein beantwortet. Fragt aber ein anderer hier, wird meist geprahlt und natürlich mit ja geantwortet. Warum? Sagt man nein, verlieren die anderen die Achtung und den Respekt vor dir. Und Achtung und Respekt sind hier wichtig!

Du fragst dich bestimmt, an welchem Ort ich mich befinde? Was ist das für ein Ort, an dem ich mich selbst belügen muss und Respekt und Achtung eine so große Rolle spielen? Es ist ein kalter, emotionsloser Ort, der Knast!

Die eigentlich wichtige Frage ist also nicht: WAR es das wert, sondern IST es das wert? Diese Frage solltest du dir vor jeder Tat, die du begehst, stellen! Bist du ehrlich zu dir selbst, kannst du mit nein antworten. Denn zum Beispiel wenn jemand vor dir steht und dich provoziert und du schlägst ihn daraufhin, fühlst du dich gut und unbesiegbar! Aber am nächsten Tag, dann, wenn die Polizei vor deiner Tür steht mit dem Haftbefehl wegen Körperverletzung, kommt sie, die Frage: War es das wert?

Für ein paar Sekunden hattest du das Gefühl der Unbesiegbarkeit und für ein paar Jahre jetzt das Gefühl der Alleinheit und die Frage:

War es das wert? Deswegen frag dich immer vor deiner Tat: Ist es das wert? Ein guter Rat von jemand, der sich fragt: War es das wert? Nein, es ist es nicht! 